\title{
PYODERMA GANGRENOSUM WITH INFLAMATORY BOWEL DISEASE
}

\author{
P. Guru Prasad ${ }^{1}$, S. Jhansi Lakshmi², P. V. Krishna Rao ${ }^{3}$, M. Parvathi' ${ }^{4}$ B. Durga Bhavani ${ }^{5}$
}

\section{HOW TO CITE THIS ARTICLE:}

P. Guru Prasad, S. Jhansi Lakshmi, P. V. Krishna Rao, M. Parvathi, B. DurgaBhavani. "Pyoderma gangrenosum with inflammatory bowel disease". Journal of Evolution of Medical and Dental Sciences 2015; Vol.4, Issue 03 January 08; Page: 489-492, DOI:10.14260/jemds/2015/72

\begin{abstract}
Pyoderma gangrenosum (PG) is a chronic, painful ulcerated skin disease of unknown etiology. Its association with inflammatory bowel disease like ulcerative colitis is common. The lesions generally appear during the course of active bowel disease, frequently concur with exacerbations of colitis, sometimes with inactive ulcerative colitis. 15 to $20 \%$ of patients with Pyoderma gangrenosum have ulcerative colitis and 0.5 to $5 \%$ of patients with ulcerative colitis have Pyoderma gangrenosum. occasionally skin lesions may preceed active inflammation of colon. Here we report a case of 50 year old female presenting with large ulcerated lesion over the anterior aspect of the middle $1 / 3 \mathrm{rd}$ of left leg associated with severe pain and bloody discharge. skin biopsy shows epidermis with necrosis and diffuse dense neutrophilic infiltrate in superficial epidermis extending into the deep dermis. Colonoscopy shows features of ulcerative colitis. Patient showed rapid response with systemic steroids and specific treatment with 5-amino salicylic acid (mesalamine). ulcer healed within 6 weeks and followed for 3months with no recurrence.
\end{abstract}

KEYWORDS: Pyoderma gangrenosum (PG), ulcerative colitis (UC), 5 amino salicylic acid (5 ASA).

INTRODUCTION: Pyoderma gangrenosum is a rare distinctive non bacterial inflammatory skin disease with chronic, painful ulcerations, which was $1^{\text {st }}$ described in 1930 by Brunsteing et al 1 . Although the etiology is not known It is associated with systemic disease in $50 \%$ of cases and idiopathic in $50 \%{ }^{1}$. It is a manifestation of altered immunity and impaired neutrophil chemotaxis. we report a 50 year female patient with clinically silent but active and extensive bowel disease diagnosed on sigmoidoscopy and biopsy.

CASE REPORT: A 50 Year old female, house wife, came to the dermatology department complaining of large non healing ulcer over the shin of left leg since 1 month. Pain is out of proportion to the ulcer and it is associated with constitutional symptoms like fever, athralgia and myalgia. She had past history of recurrent episodes of bloody diarrhea and rectal bleeding, and diagnosed by gastroenterologist as ULCERATIVE COLITIS.

Dermatological examination showed single ulcer of size $20 \mathrm{~cm}$ x15 cm over the middle $1 / 3^{\text {rd }}$ of left leg, with well-defined elevated violaceous borders and undermined edge, base is covered with necrotic slough and bloody discharge.

On systemic examination wheeze present suggestive of bronchial asthma, where as other systems were found to be with in normal limits. Complete blood count HB -10.6 gm /dl, TC - 6000 cells/mm3, DC - P 62\% L 34\% E $2 \%$ M 1\%, platelet count 3.1 lakh $/ \mathrm{mm} 3$, ESR - $85 \mathrm{~mm} / 1^{\text {st }} \mathrm{hr}$. peripheral smear showed mild degree of normocytic hypochromic anemia and CRP - Negative, AEC normal, FBS - $90 \mathrm{mg} / \mathrm{dl}$, total serum proteins $-6.2 \mathrm{gm}$ (s. albumin $4.1 \mathrm{gm}$, s. globulin 2.7gm), liver function tests, Renal function tests were with in normal limits. 
Mantoux test negative, Pathergy test negative, RA factor - negative, ANA - negative, pus\& stool culture were sterile. Chest $\mathrm{x}$ ray - features suggestive of bronchial asthma, sputum - negative for AFB, Ultra sound abdomen - normal, VCTC - NR, VDRL -NR.

Skin biopsy from the edge of the ulcer - necrosis and diffuse dense neutrophilic infiltrate in superficial epidermis extending into the dermis with perivascular infiltrate. Colonoscopy - red colonic mucosa with multiple diffuse ulcerations and erosions. Colonic biopsy - Suggestive of ulcerative colitis. Patient was admitted and treated with oral prednisolone $40 \mathrm{mg} /$ day, gradually tapered 10 mg every 2 weeks upto 6 weeks, along with mesalamine $800 \mathrm{mg}$ TID and supportive treatment. Ulcer completely healed within 6 weeks and the case was followed for 3 months and was in remission. The diagnosis of pyoderma gangrenosum was made as it fulfilsl 2 major criteria (Rapid progression of painful necrotic ulcer, Exclusion of other causes of ulceration) and 3 minor criteria (ulcerative colitis associated with Pyoderma gangrenosum, Histopathological findings, Rapid response with corticosteroids) of pyoderma gangrenosum.

DISCUSSION: Pyoderma gangrenosum has been reported in india and worldwide. ${ }^{2,3}$ Associated systemic diseases reported are ulcerative colitis, crohn's disease, ${ }^{4}$ rheumatoid arthritis, ${ }^{5}$ seronegative arthritis, hematological malignancies, collagen vascular diseases, monoclonal gammopathy, hepatic and pancreatic diseases, wegners granulomatosis, neutrophilic dermatosis. ${ }^{6}$ The prevelance of Pyoderma gangrenosum associated with ulcerative colitis has been reported to range from 30 to 60 $\%,{ }^{7}$ symptoms of ulcerative colitis may preceed, follow or be concomitant with Pyoderma gangrenosum.

In our case patient had ulcerative colitis since 2 years. Even though the disease is active, clinically it is silent. pathergy is negative. ${ }^{3,8}$ It has been suggested that there is preferential occurance of skin lesions in early onset ulcerative colitis in younger patients. In late onsent ulcerative colitis pyoderma gangrenosum appears less frequently But in our case it appeared at the age of 52 years in contrast to previous observations.

Thronton et $\mathrm{al}^{8}$ found that chronic ulcerative colitis was present at an average of 10 years before appearance of pyoderma gangrenosum. In our case patient developed skin lesions within 2 years of bowel disease.

Skin lesions gradually appear during clinically active bowel disease.7,8 In patients of Thronton et $\mathrm{al}^{8}$ lesions of pyoderma gangrenosum appeared for the first time during clinically quiscent phase of colitis, eventhough colonoscopy is suggestive of active ulcerative colitis.In our case patient developed pyoderma gangrenosum inclinically quiescent phase of ulcerative colitis.

The treatment of Pyoderma gangrenosum is mostly unsatisfactory; The aim is to treat the underlying disease. Numerous modes of treatment have been tried with varying outcomes. Most frequently used treatments include topical, intralesional, oral and pulse steroid therapy, cyclophosphomide, azathioprine antibiotics sulfadrugs, dapsone, clofazamine, minocycline, cyclosporine. ${ }^{7}$ cyclosporine has been reported as a very effective drug in Pyoderma gangrenosum at the dose of 6 to $10 \mathrm{mg} / \mathrm{kg} /$ day with healing in 1 to 3 months.6,9

In our patient in view of underlying ulcerative colitis patient was treated with prednisolone and $5 \mathrm{ASA},{ }^{3}$ patient showed good response within 6 weeks.

Although seen in association with many systemic disorders, ulcerative colitis still forms the most significant association with Pyoderma gangrenosum. In all the patients presenting with 
Pyoderma gangrenosum. colonoscopy \& rectal biopsy must be carried out even without any bowel symptoms. This will help in early detection of underlying bowel involvement and proper management

\section{REFERENCES:}

1. Brunsting LA, Goeckerman WH and O'Leary PA Pyoderma (Ecthyma) gangrenosum: Clinical and experimental obThronton JR, Teague RH, Low-Beer TS et al Pyoderma gangrenosum and ulcerative colitis, Gut, 1980; 21: 247-248.

2. Arnti N, Bhushan K, Radotra B, et al. Asymptomatic ulcerative colitis and pyoderma gangrenosum. Indian J Dermatol Venereol Leprol 1990; 56: 221.

3. Powell FC, Su WPD, Perry H. Pyoderma gangrenosum: Classification and management. J Am Acad Dermatol 1996; 34: 395-409.

4. Schoetz DJ, Coller JA and Veidenheimer MC Pyoderma gangrenosum and Crohn's disease, Dis Colon Rectum, 1983; 26 : 155-158.

5. Stolman LP, Rosenthan D, Yaworsky R et al Pyoderma gangrenosum and rheumatoid arthritis, Arch Dermatol, 1975; $111:$ 1020-1023.

6. Wolff K, Stingl G. Pyoderma gangrenosum. In: Fitzpatrick TB, Eisen AB, Wolff K, et al. eds, Dermatology in General Medicine. New York: MCGrawhill, 1993; 1171-1182.

7. Basler RSW. Ulcerative colitis and the skin. Med Clin North Am 1980; 64: 941.

8. Thronton JR, Teague RH, Low-Beer TS et al Pyoderma gangrenosum and ulcerative colitis, Gut, 1980; 21: 247-248.

9. Chow RKP, HO VC. Treatment of pyoderma gangrenosum. J Am Acad Dermatol 1996; 34: 1047 1059.

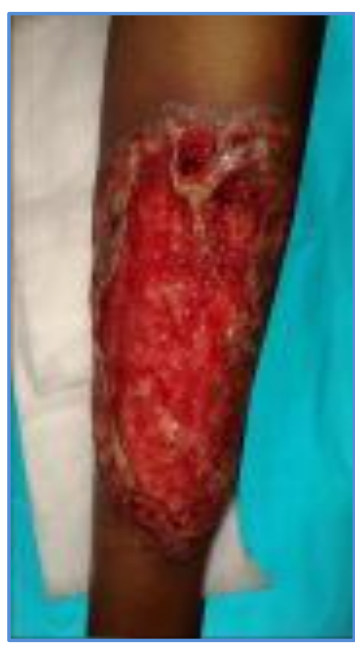

At admission

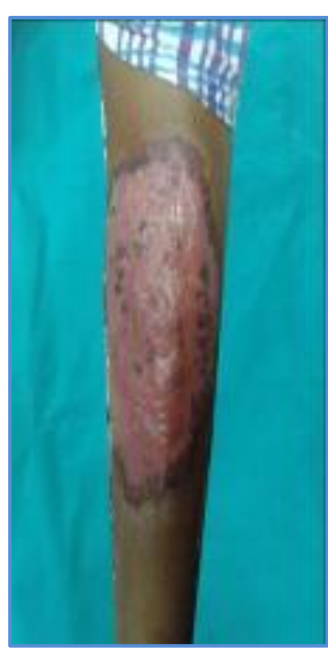

After 6 weeks

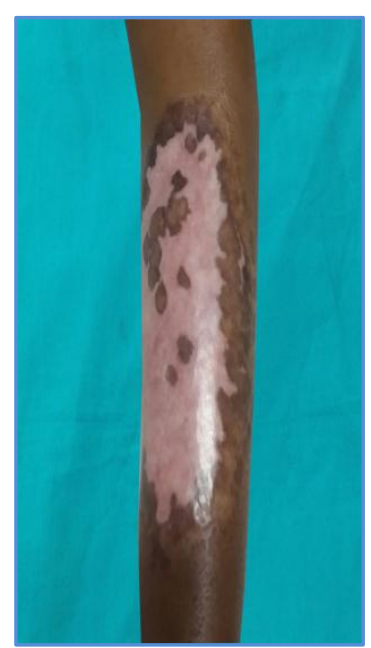

At Present

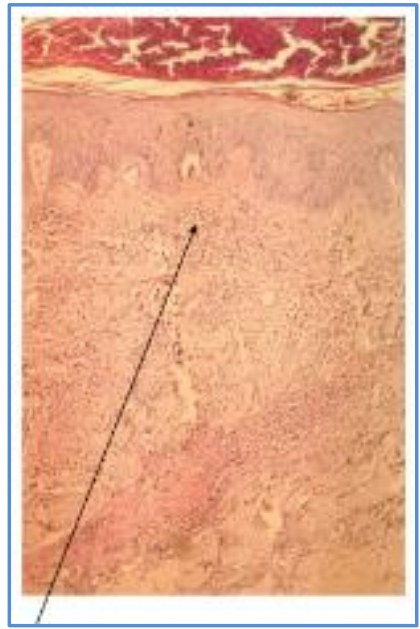

Histopathology 


\section{AUTHORS:}

1. P. Guru Prasad

2. S. Jhansi Lakshmi

3. P. V. Krishna Rao

4. M. Parvathi

5. B. DurgaBhavani

\section{PARTICULARS OF CONTRIBUTORS:}

1. Professor, Department of Dermatology, Andhra Medical College, Vizag.

2. Assistant Professor, Department of DVL,Andhra Medical College, Vizag.

3. Assistant Professor, Department of Dermatology, Andhra Medical College, Vizag.
4. Assistant Professor, Department of Dermatology, Andhra Medical College, Vizag.

5. Junior Resident, Department of DVL, Andhra Medical College, Vizag.

\section{NAME ADDRESS EMAIL ID OF THE} CORRESPONDING AUTHOR:

Dr. P. Guru Prasad,

Professor, Department of Dermatology, Andhra Medical College, Vizag.

E-mail: gppatnala@yahoo.co.in

Date of Submission: 23/12/2014.

Date of Peer Review: 24/12/2014.

Date of Acceptance: 31/12/2014.

Date of Publishing: 07/01/2015. 